\title{
The Association Between Changes in Insulin Sensitivity and Consumption of Tobacco and Alcohol in Young Adults: Ordinal Logistic Regression Approach
}

\author{
Dragan Skropanic $^{1}$, Gudeta Fufaa ${ }^{2}$, Bin Cai ${ }^{2}$ \\ 1. Mathematics and Statistics Department, Western Wyoming Community College 2. School of Health \\ Sciences, Walden University
}

$\square$ Corresponding author: Dragan Skropanic, dskropanic@westernwyoming.edu Disclosures can be found in Additional Information at the end of the article

\section{Abstract}

\section{Context}

Reduced insulin sensitivity is one of the traditional risk factors for chronic diseases such as type 2 diabetes. Reduced insulin sensitivity leads to insulin resistance, which in turn can lead to the development of type 2 diabetes. Few studies have examined factors such as blood pressure, tobacco and alcohol consumption that influence changes in insulin sensitivity over time especially among young adults.

\section{Purpose}

To examine temporal changes in insulin sensitivity in young adults (18-30 years of age at baseline) over a period of 20 years by taking into account the effects of tobacco and alcohol consumptions at baseline. In other words, the purpose of the present study is to examine if baseline tobacco and alcohol consumptions can be used in predicting lowered insulin sensitivity.

\section{Method}

This is a retrospective study using data collected by the Coronary Artery Risk Development in Young Adults (CARDIA) study from the National Heart, Lung, and Blood Institute. Participants were enrolled into the study in 1985 (baseline) and followed up to 2005. Insulin sensitivity, measured by the quantitative insulin sensitivity check index (QUICKI), was recorded at baseline and 20 years later, in 2005. The number of participants included in the study was 3,547. The original study included a total of 5,112 participants at baseline. Of these, $54.48 \%$ were female, and $45.52 \%$ were male; $45.31 \%$ were 18 to 24 years of age, and $54.69 \%$ were 25 to 30 years of age. Ordinal logistic regression was used to assess changes in insulin sensitivity.

Changes in insulin sensitivity from baseline were calculated and grouped into three categories (more than $15 \%$, more than $8.5 \%$ to at most $15 \%$, and at most $8.5 \%$ ), which provided the basis for employing ordinal logistic regression to assess changes in insulin sensitivity. The effects of alcohol and smoking consumption at baseline on the change in insulin sensitivity were accounted for by including these variables in the model.

\section{Results}

Daily alcohol consumption (ml/day) at baseline was not associated with changes in insulin 
sensitivity (OR $=0.998,95 \%$ CI 0.995-1.001), while the number of cigarettes consumed per day at baseline was statistically significantly associated with changes in insulin sensitivity $(\mathrm{OR}=$ 1.016, 95\% CI 1.007-1.025). Covariates such as age (OR = 1.05, 95\% CI 1.031-1.071), mean arterial blood pressure $(\mathrm{OR}=0.986,95 \% \mathrm{CI} 0.977-0.994)$, body-mass index $(\mathrm{OR}=0.951,95 \% \mathrm{CI}$ $0.936-0.965)$, race $(\mathrm{OR}=0.840,95 \%$ CI $0.735-0.960)$, and sex $(\mathrm{OR}=0.561,95 \% \mathrm{CI} 0.483-0.652)$ were significantly associated with changes in insulin sensitivity.

\section{Conclusion}

After adjusting for relevant covariates, the daily tobacco consumption at baseline was independently associated with changes in insulin sensitivity. But we were not able to replicate the association between daily alcohol consumption at baseline and changes in insulin resistance reported by other studies. Further studies in different populations and settings are warranted to examine the association between alcohol consumption and changes in insulin resistance.

Categories: Diabetes \& Endocrinology, Epidemiology/Public Health

Keywords: diabetes, insulin resistance, insulin sensitivity, ordinal logistic regression, quicki, young adults

\section{Introduction}

Insulin sensitivity is a measure of how fast a body can process glucose whereas insulin resistance is a condition in which a body is unable to efficiently process glucose. Lowered insulin sensitivity may lead to insulin resistance, which in turn leads to elevated levels of serum glucose and eventually to type 2 diabetes [1]. The most important risk factors for insulin resistance are overweight and obesity, genetics (family history), older age, and elevated blood pressure [2]. Studies that investigated the progression from lowered insulin sensitivity to insulin resistance and type 2 diabetes using longitudinal data are limited [1-2].

In this study, percent change of insulin sensitivity and its association with baseline tobacco and alcohol consumptions is investigated after having accounted for relevant co-variates. The association between insulin sensitivity and tobacco consumption has been studied in recent years, and some epidemiological characteristics were obtained although the physiological properties of this association have not been fully explained or understood [1, 3]. A study completed by Persson and colleagues in Sweden that involved men aged 35-56 provided evidence that heavy smoking was associated with a higher incidence of insulin resistance $(\mathrm{OR}=$ 2.7, 95\% CI 1.3-5.5) [4]. Some of the other studies focused on type 2 diabetes and its dependence on tobacco consumption. A meta-analysis of 25 prospective studies showed that high cigarettes consumption (defined as 20 cigarettes or more per day) placed the participants at a much higher risk for type 2 diabetes than those with lower cigarette consumption per day (combined RR $=1.61,95 \%$ CI 1.43-1.80) [5]. Another study by Zhang and colleagues showed that active smokers were at an increased risk for type 2 diabetes $(\mathrm{RR}=1.39,95 \% \mathrm{CI} 1.17-1.64)$ [6]. The association can be explained by the fact that the tobacco toxicity in the blood stream may interfere with the beta-cells' normal functioning, which in turn can trigger disruptions in normal functioning of the glucose transporters at the cellular level [5-7].

The nature of the association between insulin resistance and alcohol consumption is quite different. This has been explained by the role of alcohol in lowering the high density lipoprotein (HDL) cholesterol levels and reducing the inflammation at the cellular level [8-9]. A large prospective study involving 38,031 men indicated that moderate alcohol consumption (7.5 g per day) may lower the risk of type 2 diabetes over four years by as much as $22 \%$ (HR $=0.78$, 95\% CI 0.60-1.00) [9]. Those who consumed $7.5 \mathrm{~g}$ to $15 \mathrm{~g}$ of alcohol per day also exhibited a 
lowered risk ( $\mathrm{HR}=0.89,95 \% \mathrm{CI} 0.83-0.96)$, while those who consumed more than $15 \mathrm{~g}$ of alcohol per day exhibited neither lower nor higher risk ( $\mathrm{HR}=0.99,95 \% \mathrm{CI} 0.95-1.02)$ [9]. In yet another study, it was shown that moderate alcohol consumption may reduce the risk of type 2 diabetes in men by as much as $52 \%(\mathrm{HR}=0.48,95 \% \mathrm{CI} 0.28-0.77)$ and in women by as much as $19 \%(\mathrm{HR}=0.81,95 \% \mathrm{CI} 0.33-1.96)[10]$.

The present study used the data collected in the Coronary Artery Risk Development in (Young) Adults (CARDIA). CARDIA was initiated in 1984 by recruiting Black and White young adults aged 18-30 at four different field centers: Birmingham, Alabama; Chicago, Illinois; Minneapolis, Minnesota; and Auckland, California [11]. The original purpose of the study, which is still ongoing, was to monitor changes in cardiovascular health indicators over a long period of time. The secondary purpose of the study was to follow the participants' insulin health as well as to identify possible occurrence of prediabetes and diabetes [11-12]. The baseline characteristics were collected in 1985 (year 1). The insulin level was recorded in year 1 (1985) and year 20 (2005). The quality of the data was assured by the standard steps and procedures that the principal investigators followed in recruitment of the participants, securing confidentiality of the data, and proper management and storage of the data [11-12].

For this study, insulin sensitivity is measured by the quantitative insulin sensitivity check index (QUICKI), which has been validated as a reliable measure of insulin sensitivity [13]. In particular, using the CARDIA data set, QUICKI is calculated as:

$Q U I C K I=\frac{1}{\ln (I G)}=\frac{1}{\ln I+\ln G}$

where I is the insulin level (measured in $\mu \mathrm{mol} / \mathrm{ml}$ ) and $\mathrm{G}$ is the glucose level (measured in $\mathrm{mg} / \mathrm{dl})$. QUICKI's sensitivity and specificity have been estimated at $80 \%$ and $60 \%$, respectively [13]. One can show that QUICKI is a decreasing function of insulin and glucose, meaning that as insulin and glucose increase, the QUICKI decreases [1]. The percent change in insulin sensitivity depends on the QUICKI readings in 1985 and 2005, and is defined as follows [1]:

$\frac{Q U I C K I(1985)-Q U I C K I(2005)}{Q U I C K I(1985)} 100$

The traditional cut-off points for QUICKI are as follows: QUICKI of 0.310 or less is an indication of the presence of insulin intolerance and/or type 2 diabetes; QUICKI of 0.366 or more, on the other hand, may be an indication of absence of insulin intolerance and/or type 2 diabetes [1, 14]. Levels between 0.310 and 0.357 may indicate the presence of insulin intolerance and prediabetes, while values between 0.357 and 0.366 may be an indication of absence of insulin intolerance [12].

\section{Materials And Methods}

We sought to assess the changes in insulin sensitivity in a longitudinal setting. Ordinal logistic regression models were used wherein the percent change in insulin sensitivity was used as the main outcome variable. Insulin sensitivity was measured by the QUICKI. The study utilized the data collected by the CARDIA, and is based on year 1 (1985) and year 20 (2005) data. Main explanatory variables were alcohol and tobacco consumptions. Corresponding odds ratios and the associated confidence intervals were reported for these two main explanatory variables as well as for other variables used in the regression model, such as creatinine level, age, mean arterial blood pressure, body-mass index (BMI), serum cholesterol, race, and sex (gender). 
The percent change in insulin sensitivity depends on the QUICKI readings in 1985 and 2005 and is defined as follows:

$\frac{Q U I C K I(1985)-Q U I C K I(2005)}{Q U I C K I(1985)} 100$

To categorize the percent change in insulin sensitivity, the cut-off points of $8.5 \%$ and $15 \%$ were used. The first cut-off point of $8.5 \%$ was discovered to be a significant mean difference, while the second cut-off point is calculated as:

$\frac{0.357-0.310}{0.310} 100$

These cut-off points will provide the necessary categories in the dependent (outcome) variable. In particular, the first category consists of percent change values of less than $8.5 \%$, the second category of percent change values of $8.5 \%$ to at most $15 \%$, and the third category of percent change values of more than $15 \%$.

STATA 13.0 (College Station, TX) software was used to code the variables, calculate QUICKI, obtain the descriptive statistics, and the results and diagnostics for the ordinal logistic regression models. Ordinal logistic regression model was used to evaluate the impact of independent variables on the ordinal categories of percent change in insulin sensitivity. Brand test was used to evaluate the parallel regression assumption. Additional tests, such as paired ttest for mean difference, one-way analysis of variance, and chi-square tests were also performed by STATA 13.0 .

\section{Results}

Initially, 5,112 participants were recruited into the study. Of these, 2,475 (48.42\%) were White and 2,637 (51.58\%) were African American. Moreover, 2,785 (54.48\%) were female and 2,327 (45.52\%) were male. The participants' average age at baseline was 24.8 years with the standard deviation of 3.6 years. The average BMI was $24.4 \mathrm{~kg} / \mathrm{m}^{2}$ with the standard deviation of 4.81 $\mathrm{kg} / \mathrm{m}^{2}$. Basic descriptive statistics for continuous demographic and biometric variables at baseline are provided in Table 1. 


\section{Cureus}

\begin{tabular}{|c|c|c|c|c|c|c|c|c|c|}
\hline Variable (Baseline) & $\begin{array}{l}\text { Number of Valid } \\
\text { Observations }\end{array}$ & Mean & $S D$ & Median & Q1 & Q3 & IQR & MIN & MAX \\
\hline Age (years) & 5,112 & 24.76 & 3.63 & 25.00 & 22.00 & 28.00 & 6.00 & 18.00 & 30.00 \\
\hline Weight (kg) & 5,096 & 70.95 & 15.52 & 68.67 & 59.42 & 79.51 & 20.09 & 43.00 & 127.00 \\
\hline Height (cm) & 5,099 & 170.35 & 9.27 & 170.00 & 163.00 & 177.50 & 14.50 & 149.50 & 193.00 \\
\hline BMI $\left(\mathrm{kg} / \mathrm{m}^{2}\right)$ & 5,095 & 24.44 & 4.81 & 23.44 & 21.15 & 26.42 & 5.27 & 17.03 & 45.85 \\
\hline $\begin{array}{l}\text { Alcohol consumption } \\
\text { (ml/day) }\end{array}$ & 5,091 & 12.08 & 21.95 & 4.77 & 0.00 & 14.70 & 14.70 & 0.00 & 335.02 \\
\hline Creatinine (mg/dl) & 5,047 & 1.04 & 0.35 & 1.00 & 0.90 & 1.20 & 0.30 & 0.50 & 15.40 \\
\hline Glucose (mg/dl) & 5,031 & 82.61 & 16.31 & 81.00 & 77.00 & 87.00 & 10.00 & 37.00 & 457.00 \\
\hline Insulin ( $\mu \mathrm{u} / \mathrm{ml})$ & 5,042 & 10.86 & 7.98 & 8.75 & 6.10 & 13.00 & 6.90 & 2.10 & 96.90 \\
\hline $\begin{array}{l}\text { Tobacco consumption } \\
\text { (number of cigarettes } \\
\text { smoked per day) }\end{array}$ & 5,112 & 4.00 & 7.94 & 0.00 & 0.00 & 5.00 & 5.00 & 0.00 & 75.00 \\
\hline $\begin{array}{l}\text { Systolic blood pressure } \\
(\mathrm{mmHg})\end{array}$ & 5,112 & 110.42 & 10.95 & 110.00 & 103.00 & 118.00 & 15.00 & 75.00 & 167.00 \\
\hline $\begin{array}{l}\text { Dlastollc blood pressure } \\
(\mathrm{mmHg})\end{array}$ & 5,111 & 68.59 & 9.62 & 68.00 & 62.00 & 75.00 & 13.00 & 0.00 & 113.00 \\
\hline MAP & 5,111 & 82.54 & 9.02 & 82.00 & 76.67 & 88.33 & 11.66 & 30.33 & 125.67 \\
\hline Cholesterol (mg/dl) & 5,063 & 176.76 & 33.47 & 174.00 & 153.00 & 197.00 & 44.00 & 72.00 & 342.00 \\
\hline
\end{tabular}

TABLE 1: Descriptive Statistics for Continuous Variables: Demographic and Biometric Characteristics at Baseline

$\mathrm{SD}=$ standard deviation, $\mathrm{Q} 1$ = 25th percentile, $\mathrm{Q} 3=$ 75th percentile, IQR = inter-quartile range (Q3-Q1), MAP = mean arterial blood pressure, $\mathrm{MIN}=$ smallest observation, $\mathrm{MAX}=$ largest observation

When it comes to alcohol consumption, the average was $12.08 \mathrm{ml} /$ day while the standard deviation was $21.95 \mathrm{ml} /$ day. The average tobacco consumption was four cigarettes/day with the standard deviation of 7.94 cigarettes/day. Stratified statistics for daily tobacco and alcohol consumptions are given in Tables 2-3 below. 


\section{Cureus}

\begin{tabular}{|c|c|c|c|c|c|}
\hline $\begin{array}{l}\text { Rank for Percent Change in Insulin } \\
\text { Sensitivity }\end{array}$ & $\begin{array}{l}\text { Number of } \\
\text { Observations }\end{array}$ & Minimum & Maximum & Mean & Std Dev \\
\hline 0 & 858 & 0 & 71 & 3.292 & 7.562 \\
\hline 1 & 859 & 0 & 52 & 2.725 & 6.804 \\
\hline 2 & 859 & 0 & 60 & 3.608 & 7.780 \\
\hline 3 & 858 & 0 & 60 & 4.623 & 8.788 \\
\hline
\end{tabular}

\section{TABLE 2: Descriptive Statistics for Daily Tobacco Consumption (cigarettes/day) According to Rank of Change in Insulin Sensitivity}

The non-zero tobacco consumption suggests that at least on some occasions all of the subjects included in the study did consume some tobacco.

\begin{tabular}{|c|c|c|c|c|c|}
\hline $\begin{array}{l}\text { Rank for Percent Change in Insulin } \\
\text { Sensitivity }\end{array}$ & $\begin{array}{l}\text { Number of } \\
\text { Observations }\end{array}$ & Minimum & Maximum & Mean & $\begin{array}{l}\text { Std } \\
\text { Dev }\end{array}$ \\
\hline 0 & 858 & 72 & 330 & 178.962 & 33.604 \\
\hline 1 & 859 & 86 & 332 & 177.681 & 33.183 \\
\hline 2 & 859 & 78 & 342 & 177.040 & 33.698 \\
\hline 3 & 858 & 93 & 303 & 176.096 & 33.053 \\
\hline \multicolumn{6}{|c|}{$\begin{array}{l}\text { TABLE 3: Descriptive Statistics for Daily Alcohol Consumption (ml/day) According to } \\
\text { Rank of Change in Insulin Sensitivity }\end{array}$} \\
\hline \multicolumn{6}{|c|}{$\begin{array}{l}\text { The non-zero alcohol consumption suggests that at least on some occasions all of the subjects included in the study did } \\
\text { consume some alcohol. }\end{array}$} \\
\hline
\end{tabular}

Insulin sensitivity levels from 1985 and 2005 were also compared. The results are summarized in Table 4 and Table 5 below. 


\section{Cureus}

\begin{tabular}{|c|c|c|c|c|c|c|c|c|c|}
\hline Variable & $\begin{array}{l}\text { Number of Valid } \\
\text { Observations }\end{array}$ & Mean & $S D$ & Median & Q1 & Q3 & IQR & MIN & MAX \\
\hline $\begin{array}{l}\text { Insulin sensitivity (QUICKI) } \\
\text { in } 1985\end{array}$ & 5,008 & 0.153 & 0.014 & 0.15 & 0.14 & 0.16 & 0.02 & 0.10 & 0.20 \\
\hline $\begin{array}{l}\text { Insulin sensitivity (QUICKI) } \\
\text { in } 2005\end{array}$ & 3,449 & 0.140 & 0.012 & 0.14 & 0.13 & 0.15 & 0.02 & 0.10 & 0.21 \\
\hline $\begin{array}{l}\text { Percent change in insulin } \\
\text { sensitivity }\end{array}$ & 3,434 & 8.27 & 9.30 & 8.79 & 2.80 & 14.33 & 11.53 & - & 37.14 \\
\hline
\end{tabular}

TABLE 4: Descriptive Statistics for Insulin Sensitivity

\begin{tabular}{|c|c|c|c|c|c|}
\hline Variabie & Number of Ubservations & Mean & Sta Dev & \multicolumn{2}{|c|}{ 95\% Confidence Interva } \\
\hline Insulin sensitivity in 1985 & 3,434 & 0.153 & 0.014 & 0.153 & 0.154 \\
\hline Insulin sensitivity in 2005 & 3,434 & 0.140 & 0.012 & 0.139 & 0.140 \\
\hline Difference $^{\star}$ & 3,434 & 0.013 & 0.015 & 0.013 & 0.014 \\
\hline
\end{tabular}

\section{TABLE 5: Insulin Sensitivity from 1985 to 2005}

The mean difference in insulin sensitivity was statistically significant (paired $t=52.822, P<0.001$ ).

The average cholesterol level was $176.76 \mathrm{mg} / \mathrm{dl}$ with the standard deviation of $33.47 \mathrm{mg} / \mathrm{dl}$. The average QUICKI at baseline was 0.153 with the standard deviation of 0.014 ; the average QUICKI in 2005 was 0.140 with the standard deviation of 0.012 . These results were also reported in the previous study [1].

The results of our analyses indicate that alcohol consumption was not a statistically significant predictor $(\mathrm{OR}=0.998,95 \% \mathrm{CI} 0.995-1.001, \mathrm{p}=0.198)$. Despite this result, alcohol consumption should be monitored as it may affect overall long-term health [10]. Moreover, tobacco consumption was statistically significant $(\mathrm{OR}=1.016,95 \%$ CI 1.008-1.025, $\mathrm{p}<0.001)$.

Further results of our investigation revealed that mean arterial blood pressure $(\mathrm{OR}=1.022,95 \%$ CI 1.012-1.033, $\mathrm{p}<0.001)$, BMI (OR = 1.063, 95\% CI 1.041-1.086, $\mathrm{p}<0.001)$, race $(\mathrm{OR}=1.283$, 95\% CI 1.082-1.521, $\mathrm{p}<0.01)$, and sex (OR $=1.792,95 \%$ CI $1.470-2.184, \mathrm{p}<0.001)$ are significant predictors of the risk of insulin resistance.

Collinearity diagnostics indicate that there were no issues as the maximum variance inflation factor was 1.30 and the minimum variance inflation factor was 1.05 .

The one-way analysis of variance results indicated that the age was significantly different among the three categories of the percent change in insulin sensitivity $(F=7.74, p<0.001)$. Similarly, mean arterial blood pressure was another significant factor $(F=6.40, p=0.002)$. 


\section{Cureus}

Furthermore, BMI showed significant difference among the three categories $(\mathrm{F}=22.75, \mathrm{p}<$ 0.001). Similarly, tobacco consumption (the number of cigarettes per day) was significantly different among the three categories of the percent change in insulin sensitivity $(\mathrm{F}=11.24, \mathrm{p}<$ 0.001).

The results of the full ordinal logistic regression model are summarized in Table 6 .

\begin{tabular}{|c|c|c|c|c|}
\hline Baseline Variable & Odds Ratio & $p$ value & \multicolumn{2}{|c|}{ 95\% Confidence Interval } \\
\hline Creatinine & 0.958 & 0.772 & 0.757 & 1.212 \\
\hline Tobacco & 1.016 & $<0.001$ & 1.008 & 1.025 \\
\hline Age & 1.051 & $<0.001$ & 1.032 & 1.071 \\
\hline MAP & 0.986 & 0.001 & 0.979 & 0.994 \\
\hline Alcohol & 0.998 & 0.198 & 0.995 & 1.001 \\
\hline BMI & 0.951 & $<0.001$ & 0.936 & 0.965 \\
\hline Cholesterol & 0.999 & 0.418 & 0.997 & 1.001 \\
\hline Race & 0.840 & 0.011 & 0.735 & 0.960 \\
\hline Sex & 0.561 & $<0.001$ & 0.483 & 0.652 \\
\hline
\end{tabular}

TABLE 6: Results from the Full Regression Model (based on $\mathbf{n}=\mathbf{3 , 3 9 4}$ )

Tobacco $=$ daily tobacco consumption, $\mathrm{MAP}=$ mean arterial blood pressure, Alcohol $=$ daily alcohol consumption, $\mathrm{BMI}=$ bodymass index

The results in Table 6 were based on the 3,394 valid cases, meaning that any subjects with missing values were not included in the model. The results of the Brant test indicated that the model satisfied the parallel regression assumption (overall $\chi 2=17.65, \mathrm{p}=0.039, \mathrm{df}=9$ ). Removal of statistically insignificant variables in the reduced regression model did not yield significantly different odds ratios for the statistically significant variables.

\section{Discussion}

This study shows that number of cigarettes consumed per day increased the risk of lowered insulin sensitivity by $1.6 \%(\mathrm{OR}=1.016,95 \%$ CI $1.008-1.025, \mathrm{p}<0.001)$. In other words, one cigarette increase per day would increase this risk by $1.6 \%$ on average. This finding corroborates current literature and the previous study in which the binary logistic regression model was used to obtain the odds ratios [1]. However, the researchers did not find a statistically significant association between alcohol consumption and change in insulin sensitivity (OR $=0.998,95 \% \mathrm{CI}$ $0.995-1.001, \mathrm{p}=0.198)$, which is different from the report in the current literature. Alcohol consumption has been reported to reduce the occurrence of lowered insulin sensitivity, although heavy alcohol consumption presents neither a benefit nor a threat to lowered insulin sensitivity $[1,9]$.

In the present study, baseline cholesterol level turned out to be a non-significant factor $(\mathrm{OR}=$ 
0.999, 95\% CI 0.997-1.001, p = 0.418), which does not corroborate the findings in the current literature. This may be due to the fact that baseline cholesterol readings were taken when the study participants were young adults. It may also suggest temporal changes in serum cholesterol may be a more meaningful indicator. Baseline serum creatinine was not a significant factor $(\mathrm{OR}=0.958,95 \%$ CI $0.757-1.212, \mathrm{p}=0.722)$ either, which might be due to the same reason as baseline cholesterol level. Studies exploring the association between serum creatinine and lowered insulin sensitivity and type 2 diabetes are rare. Only one study provided the results that lowered creatinine levels are associated with the risk of type 2 diabetes $(\mathrm{OR}=$ $1.69,95 \%$ CI 1.32-2.15) [15].

Other results of this study may be of interest for current and future investigations. In particular, the investigators discovered that sex is a statistically significant predictor $(\mathrm{OR}=$ $0.561,95 \%$ CI $0.483-0.652, \mathrm{p}<0.001$ ), meaning that men were at a higher risk than women to exhibit a lowered insulin sensitivity. Other statistically significant predictors were mean arterial blood pressure $(\mathrm{OR}=0.986,95 \% \mathrm{CI} 0.979-0.994, \mathrm{p}=0.001), \mathrm{BMI}(\mathrm{OR}=0.951,95 \% \mathrm{CI}$ $0.936-0.965, \mathrm{p}<0.001)$, and race $(\mathrm{OR}=0.840,95 \% \mathrm{CI} 0.735-0.960, \mathrm{p}=0.011)$. Results for race indicated that Whites, when compared to Blacks, were at a reduced risk of developing lowered insulin sensitivity. This may have serious implications for present and future public health intervention programs and plans.

There are several limitations that need to be mentioned. First, the study's participants come only from four urban areas of the United States: Birmingham, Alabama; Chicago, Illinois; Minneapolis, Minnesota; and Oakland, California. Despite the fact that geographical variability is represented, rural populations were not represented. Second, only two racial groups, African Americans and Whites, were included in the study. Furthermore, data for many participants were missing due to the loss of follow-ups, which may have affected the results. Finally, the data for the independent variables come from the baseline only without considering the potential changes over the 20-year period.

The strengths of the study include a large sample size, longitudinal nature of the data, geographic diversity of the participants, as well as the measurement of the bio-indicators over a long period of time with five-year visit intervals.

\section{Conclusions}

The results of the ordinal logistic regression showed that daily tobacco consumption is a significant predictor of changes in insulin regression, while daily alcohol consumption is not. In particular, the risk of lowered insulin sensitivity was increased by $1.6 \%(\mathrm{OR}=1.016,95 \% \mathrm{CI}$ 1.008-1.025) with every additional cigarette smoke per day. On the other hand, alcohol consumption was not a significant predictor of change in insulin resistance (OR $=0.998,95 \% \mathrm{CI}$ 0.995-1.001). Nonetheless, alcohol consumption should continue to be monitored as it has been linked to many other health conditions and illnesses.

Being able to predict future reduced insulin sensitivity using baseline data is challenging. Our study results showed that smoking, as well as race, sex, BMI, and arterial blood pressure can be used in predicting insulin resistance. Therefore, the implications for health care and public health are significant. Intervention programs can be designed to modify life style habits in order to reduce the risk for development of insulin resistance, and eventually, type 2 diabetes.

In future studies one may consider the effect of overall change in the independent variables (i.e. time-dependent modeling such as in survival analysis) over the designated time to better describe the association. 


\section{Additional Information \\ Disclosures}

Human subjects: Consent was obtained by all participants in this study. Walden University issued approval 02-28-14-0169217. Approval to access data sets from Biologic Specimen and Data Repository Information Coordinating Center (Bethesda, MD) was obtained, and Walden University's IRB approved the research. Present article is based on this research, and according to the data owner, no new approval is needed. . Animal subjects: All authors have confirmed that this study did not involve animal subjects or tissue. Conflicts of interest: In compliance with the ICMJE uniform disclosure form, all authors declare the following: Payment/services info: All authors have declared that no financial support was received from any organization for the submitted work. Financial relationships: All authors have declared that they have no financial relationships at present or within the previous three years with any organizations that might have an interest in the submitted work. Other relationships: All authors have declared that there are no other relationships or activities that could appear to have influenced the submitted work.

\section{References}

1. Skropanic D: Prediction of Insulin Resistance Over Time and Assessment of the Related Risk Factors in Young Adults [dissertation]. Walden University, Minneapolis, MN; 2014.

2. Foltz JL, Cook SR: Epidemiology of the metabolic syndrome and related disorders in children and adolescents. In Insulin Resistance: Childhood Precursors and Adult Disease. Zeiter PS, Nadeau KJ (ed): Humana Press, Totowa, NJ; 2008. 25-43. 10.1007/978-1-59745-192-5

3. Bergmann BC, Perrault L, Hunderdosse DM, Koehler MC, Samek AM, Eckel RH: Intramuscular lipid metabolism in the insulin resistance of smoking. Diabetes. 2009, 58:2220-2227. 10.2337/db09-0481

4. Persson PG, Carlsson S, Svanström L, Östenson C-G, Efendic S, Grill V: Cigarette smoking, oral moist snuff use and glucose intolerance. J Intern Med. 2000, 248:103-110. 10.1046/j.13652796.2000.00708.x

5. Willi C, Bodenmann P, Ghali WA, Faris PD, Cornuz J: Active smoking and the risk of type 2 diabetes: a systematic review and meta-analysis. JAMA. 2007, 298:2654-2664. 10.1001/jama.298.22.2654

6. Zhang L, Curhan GC, Hu FB, Rimm EB, Forman JP: Association between passive and active smoking and incident type 2 diabetes in women. Diabetes Care. 2011, 34:892-897. 10.2337/dc10-2087

7. Fagard RH, Nilsson PM: Smoking and diabetes: the double health hazard!. Prim Care Diabetes. 2009, 3:205-209. 10.1016/j.pcd.2009.09.003

8. Balianus DO, Taylor BJ, Irving H, Roerecke M, Patra J, Mohapatra S, Rehm J: Alcohol as a risk factor for type 2 diabetes. Diabetes Care. 2009, 32:2123-2132. 10.2337/dc09-0227

9. Joosten MM, Chiuve SE, Mukamal KJ, Hu FB, Hendricks HFJ, Rimm EB: Changes in alcohol consumption and subsequent risk of type 2 diabetes in men. Diabetes. 2011, 60:74-79. 10.2337/db10-1052

10. Rasouli B, Ahlbom A, Andersson T, Grill V, Midthjell K, Olsson L, Carlsson S: Alcohol consumption is associated with reduced risk of Type 2 diabetes and autoimmune diabetes in adults: results from the Nord-Trøndelag health study. Diabet Med. 2013, 30:56-64. 10.1111/j.1464-5491.2012.03713.x

11. National Heart, Lung, and Blood Institute (NHLBI): CARDIA Study: Protocol. Bethesda, MD; 1985.

12. National Heart, Lung, and Blood Institute (NHLBI): CARDIA Study: Year 25, Protocol. Bethesda, MD; 2012.

13. Hrebicek J, Janout V, Malincikova J, Horakova D, Cizek L: Detection of insulin resistance by simple quantitative insulin sensitivity check index QUICKI for epidemiological assessment and prevention. J Clin Endocrinol Metab. 2002, 87:144-147. 10.1210/jcem.87.1.8292\#sthash.FNwYfd2U.dpuf

14. Atabek ME, Pirgon O: Assessment of insulin sensitivity from measurements in fasting state 


\section{Cureus}

during an oral glucose tolerance test in obese children. J Pediatr Endocrinol Metab. 2007, 20:187-195.

15. Harita N, Hayashi T, Sato Kogawa K, Nakamura Y, Yoneda T, Endo G, Kambe H: Lower serum creatinine is a new risk factor for type 2 diabetes. Diabetes Care. 2009, 32:424-426.

$10.2337 /$ dc08-1265 